\title{
Clinical Stage IA Cutaneous Melanoma AJCC v8
}

National Cancer Institute

\section{Source}

National Cancer Institute. Clinical Stage IA Cutaneous Melanoma A/CC v8. NCI Thesaurus. Code C137649.

Stage IA includes: T1a, N0, M0. T1a: Tumor measuring less than $0.8 \mathrm{~mm}$ in thickness. Ulceration status: Without ulceration. N0: No regional lymph node metastasis detected. Presence of in-transit, satellite, and/or microsatellite metastases: No. M0: No evidence of distant metastasis. LDH level is not applicable. (AJCC 8th ed.) 